Rubim, AL \& Matos, DC. (2020). Comparison of types of clues on functional play in children with autism spectrum disorder. Research, Society and Development, 9(7):1-25, e465974392.

\title{
Comparação de tipos de pistas sobre brincar funcional em crianças com transtorno do espectro autista
}

\section{Comparison of types of clues on functional play in children with autism spectrum disorder}

Comparación de tipos de pistas sobre el juego funcional en niños con trastorno del espectro autista

Recebido: 10/05/2020 | Revisado: 11/05/2020 | Aceito: 13/05/2020 | Publicado: 22/05/2020

\section{Amanda Lima Rubim}

ORCID: https://orcid.org/0000-0002-7773-6775

Universidade Ceuma, Brasil

E-mail: amandalrubim@gmail.com

Daniel Carvalho de Matos

ORCID: https://orcid.org/0000-0002-6793-0101

Universidade Ceuma e Universidade Federal do Maranhão, Brasil

E-mail: dcmatos23@hotmail.com

\section{Resumo}

Crianças com Transtorno do Espectro Autista (TEA) costumam apresentar déficits em diversos repertórios, incluindo brincar de forma funcional. Na literatura da Análise do Comportamento Aplicada, destacaram-se pesquisas que investigaram efeitos do uso de roteiros fotográficos, representando ações com brinquedos, e outros tipos de pistas sobre o estabelecimento de desempenhos independentes em crianças com TEA. O responder sob controle de fotos foi demonstrado a partir de diferentes níveis de pistas, como instruções verbais e modelação. No entanto, os estudos prévios não isolaram os efeitos de cada uma delas. O presente estudo teve como objetivo comparar os efeitos de pistas do tipo instrução verbal e modelação em duas crianças com TEA de 10 anos, e mediante um delineamento de tratamentos alternados, quanto ao estabelecimento de ações de brincar na presença de roteiros fotográficos. As intervenções foram eficazes para o desenvolvimento de desempenhos independentes em ambas as crianças. No caso de uma delas, diferenças foram mais 
acentuadas, com maior eficiência da pista de modelação. Para a outra criança, não houve diferenças entre as pistas quanto a eficiência do ensino. Sondas de controle de estímulos com diferentes sequências de apresentação de fotos indicaram estabelecimento do responder sob controle das fotos.

Palavras-chave: Transtorno do espectro autista; Roteiros fotográficos; Instrução verbal; Modelação.

\begin{abstract}
Children with Autism Spectrum Disorder (ASD) commonly present deficits in several repertoires, including play behavior. In the literature of Applied Behavior Analysis, there were studies, which investigated the effects of use of photographic activity schedule, with pictures portraying actions with toys, and other type of cues on the establishment of independent performance in children with ASD. Responding under the control of pictures was demonstrated through different levels of cues, such as verbal instructions and modeling. However, previous research did not isolate the effects of the cues. The current study had the goal of comparing the effects of two cues, verbal instruction and modeling, in two 10-year old children with ASD, and through an alternating treatments design, as to the establishment of actions with toys in the presence of pictures representing them. The interventions were effective to the development of independent performance in both children. In the case of one of them, differences were more evident, since the modeling cue was more efficient. For the other child, there were no differences in efficiency, considering the two cues. Stimulus control probes with different sequences of pictures presented, suggested the establishment of responding under the control of the pictures.
\end{abstract}

Keywords: Autism spectrum disorder; Photographic activities schedule; Verbal instruction; Modeling.

\title{
Resumen
}

Los niños con trastorno del espectro autista (TEA) suelen presentar déficits en varios repertorios, incluido el juego funcional. En la literatura sobre Análisis de comportamiento aplicado, se destacó la investigación que investigó los efectos del uso de guiones fotográficos, que representan acciones con juguetes y otros tipos de pistas sobre el establecimiento de actuaciones independientes en niños con TEA. La respuesta bajo control fotográfico se demostró a partir de diferentes niveles de pistas, como instrucciones verbales y modelos. Sin embargo, estudios previos no han aislado los efectos de cada uno. El presente estudio tuvo 
como objetivo comparar los efectos de la instrucción verbal y las pistas de modelado en dos niños con TEA de 10 años, y mediante el diseño de tratamientos alternativos, con respecto al establecimiento de acciones de juego en presencia de guiones fotográficos. Las intervenciones fueron efectivas para el desarrollo de actuaciones independientes en ambos niños. En el caso de uno de ellos, las diferencias se acentuaron más, con una mayor eficiencia de la ejecución del modelado. Para el otro niño, no hubo diferencias entre las pistas con respecto a la eficiencia de la enseñanza. Las sondas de control de estímulo con diferentes secuencias de presentación de fotos indicaron el establecimiento de una respuesta bajo el control de las fotos.

Palabras clave: Desorden del espectro autista; Calendario de actividades fotográficas; Instrucción verbal; Modelado.

\section{Introdução}

O Transtorno do Espectro Autista (TEA) engloba quadros relacionados à incorporação de um grupo de déficits qualitativos e quantitativos nos aspectos sociais e comportamentais da comunicação verbal ou não-verbal (Brunoni, Mercadante \& Schwartzman, 2014), e nos padrões de comportamentos restritos e repetitivos (American Psychiatric Association, 2013). Constata-se que um componente significativo da caracterização do TEA envolve déficits no desenvolvimento social.

Dentre repertórios importantes para o desenvolvimento, e nos quais crianças com diagnóstico de TEA costumam apresentar déficits, destaca-se o brincar funcional (Williams, Redd \& Costall, 2001). Para a Análise do Comportamento Aplicada (ABA), o brincar é um comportamento operante, sendo sensível às consequências que produz e selecionado por elas (Brito, 2011). Um dos formatos de intervenção, envolvendo esse tipo de repertório em aprendizes com desenvolvimento atípico, emprega tentativas discretas com práticas repetidas. São administradas várias tentativas ou oportunidades para um aprendiz responder. Uma tentativa bem-sucedida compreende início, meio e fim definidos. Em outras palavras, um terapeuta apresenta uma instrução que fornece contexto para emissão de uma resposta pelo aprendiz, e esta resulta em reforço.

Como exemplo, o terapeuta poderia fornecer um modelo de ação de mover um carrinho de brinquedo para frente e para trás, junto com a instrução verbal "faça igual" para uma dada criança. Esta emite a ação de imitar o modelo com o carrinho e, em seguida, o terapeuta elogia e permite o acesso a um estímulo reforçador arbitrário de maior preferência. 
$\mathrm{Na} \mathrm{ABA}$, descrições sobre o formato de tentativas discretas costumam comparecer em relatos de pesquisas científicas, e manuais de intervenção com foco em TEA e quadros relacionados (Akers, Higbee, Pollard, Pellegrino \& Gerencser, 2016; Allen \& Cowan, 2008; Goulart \& Assis, 2002; Lear, 2004; Lovaas, 1987; Matos, 2006; Matos \& Matos, 2018; Matos, Matos, Araújo, Ribeiro \& Melo, 2018; Matos, Silva, Firmo \& Matos, 2020; Phillips \& Vollmer, 2012; Smith, 2001; Varella \& Souza, 2018).

O ensino de habilidades, como o brincar funcional em crianças com TEA, demanda procedimentos que estabeleçam o responder sob controle de estímulo apropriado. Na ABA, estratégias que combinam manipulação de dicas, e seu posterior esvanecimento, frequentemente são empregadas com o propósito de estabelecer repertórios sob controle discriminativo (Lear, 2004; Matos, 2016). Quanto ao caso do brincar funcional mais especificamente, destaca-se na literatura científica pesquisas que manipularam roteiros fotográficos, representando o passo a passo de várias ações com brinquedos. Nesses estudos, os efeitos do uso de roteiros, combinados com outros tipos de pistas, foram medidos sobre o estabelecimento de desempenhos independentes quanto a ações de brincar (Akers et al., 2016; Phillips \& Vollmer, 2012; Matos et al., 2018).

Akers et al. (2016) avaliaram os efeitos do uso de roteiros fotográficos sobre o estabelecimento de repertórios de brincar em um parque, por parte de três crianças com TEA entre 4 e 5 anos. Os roteiros consistiam em fotos organizadas, e que deveriam servir a função de pistas para a realização de sequências de ações de brincar. Em momentos de recreação, as crianças engajavam-se em estereotipias, ao invés de demonstrarem comportamentos de brincar de forma funcional. As ações se relacionavam ao que crianças tipicamente fazem em um ambiente de parque como, por exemplo, escorregar em um escorregador. Fotos, retratando ações como essa, eram organizadas em um caderno e, cada página, apresentava uma foto diferente. Durante a linha de base, as crianças não demonstraram autonomia em realizar as ações representadas pelos roteiros. $\mathrm{Na}$ intervenção, ajuda física era fornecida para a realização de ações, e critérios arbitrários foram definidos para seu esvanecimento. Desempenhos independentes de pista resultavam no acesso a fichas, que poderiam ser posteriormente trocadas por itens de preferência. Todas as crianças aprenderam a seguir os roteiros com autonomia, e os desempenhos corretos foram mantidos em follow up duas semanas depois.

Phillips \& Vollmer (2012) manipularam roteiros fotográficos para ensinar sequências de respostas de brincar funcional em três crianças com desenvolvimento atípico (duas com atraso de linguagem e uma com TEA). O trabalho foi desenvolvido em uma sala próxima à sala de aula de uma escola. O ambiente continha mesas, cadeiras e brinquedos. Quatro 
conjuntos de brinquedos (e.g., uma fazenda com um trator, uma cavalo, vaca, etc.) foram selecionados. Diferentes fotos, cada uma representando uma ação, foram definidas e organizadas em um caderno (uma foto por página). As crianças apresentavam pré-requisitos para a pesquisa (e.g., discriminar objetos como ouvinte, seguir instruções, realizar pareamentos visuais-visuais arbitrários, relacionando objetos com os modelos de suas fotos). Também aprenderam a manipular o caderno, folheando cada página e apontando para ela. Foi conduzido um teste de instrução geral, para assegurar que as crianças não conseguiam realizar ações a partir das fotos, diante de uma instrução geral como "faça o que está na foto".

Após uma linha de base, a partir da qual as crianças não realizaram ações com brinquedos na presença de fotos que as representavam, uma intervenção entrou em vigor. Respostas independentes eram reforçadas com elogios, e erros, ou ausência de resposta, corrigidos com até cinco tipos de ajuda: 1) instrução geral para realizar o que estava na foto; 2) instrução específica para realizar a ação; 3) o experimentador apontava para os objetos relevantes para a realização de uma ação, enquanto fornecia uma instrução específica); 4) modelação (o experimentador demonstrava o que tinha que ser feito); 5) ajuda física (o experimentador corrigia a criança fisicamente). Como resultado, o procedimento foi eficaz para o estabelecimento de sequências de respostas corretas em todos os aprendizes. Houve alguma generalização de desempenho independente com brinquedos não treinados diretamente. Além disso, sondas de avaliação, em que as fotos eram apresentadas sob diferentes sequências, sugeriram controle de estímulos do responder pelas fotos.

Matos et al. (2018) conduziram um trabalho, semelhante ao que foi desenvolvido por Phillips \& Vollmer (2012), com o propósito de testar a generalidade do procedimento com outras crianças com desenvolvimento atípico. Um elemento novo, quanto ao estudo de Matos et al., referiu-se ao fato de que as quatro crianças da pesquisa (três com atraso de linguagem e uma com TEA) não apresentavam experiência prévia com roteiros fotográficos para estabelecimento de repertórios, diferente dos casos das crianças da literatura anterior. Todas as condições do estudo anterior foram também administradas (e.g., avaliação de prérequisitos, ensino do uso do caderno com fotos; teste de instrução geral; linha de base; intervenção com até cinco tipos de pista; sonda de verificação de controle de estímulos com nova sequência de fotos no caderno). Como resultado, todas as crianças participantes adquiriram os repertórios de brincar com autonomia, e sondas de controle de estímulos sugeriram que o responder foi mantido sob controle das fotos. Além disso, para uma das crianças, foi verificada a generalização de desempenho independente com dois conjuntos de brinquedos não ensinados diretamente. 
Os três estudos apresentados, sobre ensino de brincar funcional com uso de roteiros fotográficos (Akers et al., 2016; Phillips \& Vollmer, 2012; Matos et al., 2018), demonstraram que os roteiros foram variáveis importantes para o estabelecimento de ações de brincar de forma independente. A literatura documenta ainda que o uso de roteiros visuais com imagens e/ou textuais também foi eficaz para a aquisição de outros repertórios em indivíduos com desenvolvimento atípico, relacionados, por exemplo, a atividades laborais e tarefas vocacionais (Minarovic \& Bambara, 2007; Sowers, Verdi, Bourbeau \& Sheehan, 1985; Wacker \& Berg, 1983; Wacker, Berg, Berrie, \& Swatta, 1985); cuidados da vida diária (Pierce \& Schreibman, 1994); preparos de refeições (Johnson \& Cuvo, 1981; Martin, Rusch, James, Decker, \& Trtol, 1982); comunicação durante a realização de atividades de lazer (Macduff, Krantz \& Mcclannahan, 1993).

Ainda sobre o brincar funcional, foi dito que, nos casos de duas das pesquisas mencionadas (Phillips \& Vollmer, 2012; Matos et al., 2018), diferentes níveis de pistas foram utilizados para o estabelecimento do responder sob controle das fotos. Dentre elas, havia, por exemplo, instruções verbais específicas e o fornecimento de modelos não verbais de ações por um experimentador. Quando ajuda era necessário, um dos níveis correspondia à apresentação de uma instrução específica. Caso não fosse suficiente como correção, outros níveis de ajuda eram apresentados. Ainda que a literatura prévia tenha demonstrado que o ensino foi eficaz para as crianças com TEA participantes, não foi conduzida uma investigação sobre que tipo de pista poderia ter sido mais eficiente para cada criança, o que torna tal investigação uma meta importante.

Sendo assim, a presente pesquisa teve o objetivo de comparar, para duas crianças com TEA no contexto de um laboratório de avaliação, pesquisa e intervenção de uma Universidade privada, os efeitos de dois tipos de pista (instrução verbal e modelação) sobre o estabelecimento de respostas de brincar funcional sob controle de fotos que as representavam, e que foram organizadas em cadernos. As fotos representavam roteiros para a realização de ações. Foi considerado que a pista que favorecesse mais rapidamente o estabelecimento de um repertório independente, seria a mais eficiente.

\section{Materiais e Métodos}

Em uma pesquisa buscam-se novos conhecimentos ou saberes. Nas pesquisas laboratoriais, as condições são mais controladas, como preconizam Pereira, Shitsuka, Parreira \& Shitsuka (2018) em relação às pesquisas em campo. O presente trabalho consistiu em um 
estudo experimental, realizado no contexto de um laboratório de pesquisa e intervenção em TEA de uma Universidade privada, sob responsabilidade do segundo autor. Uma pesquisa experimental compreende a manipulação de variáveis independentes (VI), e investigação de seus efeitos sobre uma variável dependente (VD). A principal variável dependente, quanto a este trabalho, consistiu no número de respostas de brincar funcional emitidas corretamente na presença de fotos que as representavam. Dois tipos de intervenção foram programados para o ensino de ações com brinquedos (um para cada intervenção) em duas crianças com TEA. Em um dos casos, pistas de instrução verbal para a realização de ações eram apresentadas e, no outro caso, pistas de modelação (detalhes a respeito das intervenções são apresentados ao longo da seção de método). O tipo de delineamento experimental de caso ou sujeito único utilizado para medir controle das VIs sobre a VD foi tratamentos alternados intra-participante com linha de base inicial. A partir desse tipo de delineamento, duas ou mais condições de intervenção são administradas em rápida alternância, visando a aquisição de um determinado repertório. Os efeitos sobre o repertório são medidos e comparados com o intuito de identificar a intervenção mais eficiente, ou que demanda menos tempo de exposição para a aquisição do repertório. (detalhes sobre o delineamento são apresentados mais adiante) (Cooper, Heron \& Heward, 2006; e Pereira et al., 2018).

\subsection{Participantes}

Participaram do estudo duas crianças, com dez anos de idade: P1, do sexo masculino, e P2, do sexo feminino, residentes na cidade de São Luís - Maranhão, com o diagnóstico de TEA. Ambas as crianças recebem atendimentos fundamentados em Análise do Comportamento Aplicada (ABA) duas vezes por semana, no Laboratório de Avaliação, Pesquisa e Intervenção em Transtorno do Espectro Autista (LAPITEA) de uma Universidade privada (Universidade CEUMA).

\subsection{Ambiente de coleta}

Sessões experimentais foram conduzidas em ambiente estruturado do laboratório LAPITEA. Tratou-se de uma sala equipada com mesa e cadeira, onde experimentadora e criança sentavam na frente um do outro, permitindo sessões individualizadas. 


\subsection{Instrumentos e materiais}

Foram utilizados dois tipos de brinquedos por criança. Para cada caso foram selecionadas fotos representando ações com os brinquedos, e nas quais as crianças deveriam se basear para emitir ações. As fotos representavam, portanto, roteiros que orientavam as ações e eram independentes entre si, o que permitiu a organização de diferentes sequências de apresentação. Cada foto representava as mãos de um adulto, realizando uma determinada ação com um brinquedo. Nas ocasiões em que as fotos eram apresentadas para as crianças, os brinquedos permaneciam disponíveis para a realização das ações especificadas por elas. As fotos das ações com cada brinquedo eram apresentadas em um caderno. Cada página do caderno compreendia uma foto de uma ação diferente. Ao longo da realização das ações, cada criança deveria folhear o caderno, emitindo respostas até chegar à última página em que a informação "fim" aparecia impressa. Para a sistematização das respostas das crianças, foram utilizadas folhas de registro personalizadas. A Tabela 1 apresenta nove ações realizadas com cada brinquedo de ambas as crianças, e que foram representadas por fotos.

Tabela 1. Ações realizadas com brinquedo 1 (hambúrguer) e 2 (bola) por P1 (duas primeiras colunas), e ações realizadas com brinquedo 1 (sorvete) e 2 (torta) por P2 (duas últimas colunas).

\begin{tabular}{|c|c|c|c|}
\hline Brinquedo 1 (P1) & Brinquedo 2 (P1) & Brinquedo 1 (P2) & Brinquedo 2 (P2) \\
\hline $\begin{array}{l}\text { Encaixar o tomate } \\
\text { no pão do } \\
\text { hambúrguer. }\end{array}$ & $\begin{array}{l}\text { Encaixar a peça } \\
\text { verde da bola. }\end{array}$ & $\begin{array}{l}\text { Encaixar a bola de } \\
\text { sorvete lilás na } \\
\text { casquinha. }\end{array}$ & $\begin{array}{l}\text { Encaixar um pedaço } \\
\text { marrom no canto } \\
\text { superior na fatia } \\
\text { rosa de torta. }\end{array}$ \\
\hline Encaixar a alface. & $\begin{array}{l}\text { Encaixar a peça } \\
\text { azul da bola. }\end{array}$ & $\begin{array}{l}\text { Encaixar a bola de } \\
\text { sorvete azul na } \\
\text { casquinha. }\end{array}$ & $\begin{array}{c}\text { Encaixar um doce } \\
\text { amarelo em formato } \\
\text { de boneco no canto } \\
\text { inferior na fatia rosa } \\
\text { de torta. }\end{array}$ \\
\hline Encaixar o ovo. & $\begin{array}{c}\text { Encaixar a peça } \\
\text { vermelha da bola. }\end{array}$ & $\begin{array}{l}\text { Encaixar a bola de } \\
\text { sorvete branca na } \\
\text { casquinha. }\end{array}$ & $\begin{array}{l}\text { Encaixar um doce } \\
\text { redondo marrom no } \\
\text { canto direito na } \\
\text { fatia rosa de torta. }\end{array}$ \\
\hline $\begin{array}{l}\text { Encaixar a carne de } \\
\text { hambúrguer. }\end{array}$ & $\begin{array}{l}\text { Encaixar a peça } \\
\text { verde da bola. }\end{array}$ & $\begin{array}{l}\text { Encaixar o sorvete } \\
\text { lilás com a } \\
\text { casquinha em uma } \\
\text { capa. }\end{array}$ & $\begin{array}{l}\text { Encaixar uma bola } \\
\text { de chocolate no } \\
\text { canto esquerdo na } \\
\text { fatia rosa de torta. }\end{array}$ \\
\hline
\end{tabular}




\begin{tabular}{|c|c|c|c|}
\hline Encaixar o cheddar. & $\begin{array}{l}\text { Encaixar a peça } \\
\text { azul da bola. }\end{array}$ & $\begin{array}{c}\text { Encaixar o sorvete } \\
\text { branco com a } \\
\text { casquinha em uma } \\
\text { capa. }\end{array}$ & $\begin{array}{l}\text { Encaixar uma cereja } \\
\text { no meio da fatia } \\
\text { rosa de torta. }\end{array}$ \\
\hline $\begin{array}{l}\text { Colocar ketchup } \\
\text { (simbólico). }\end{array}$ & $\begin{array}{c}\text { Encaixar a peça } \\
\text { vermelha da bola. }\end{array}$ & $\begin{array}{l}\text { Encaixar o sorvete } \\
\text { azul com a } \\
\text { casquinha em uma } \\
\text { capa. }\end{array}$ & $\begin{array}{l}\text { Encaixar um doce } \\
\text { em formato de urso } \\
\text { marrom em um } \\
\text { cupcake amarelo. }\end{array}$ \\
\hline $\begin{array}{c}\text { Fechar o } \\
\text { hambúrguer com } \\
\text { outro pão. }\end{array}$ & $\begin{array}{l}\text { Encaixar a peça } \\
\text { verde da bola. }\end{array}$ & $\begin{array}{l}\text { Colocar o sorvete } \\
\text { azul completo em } \\
\text { uma tigela. }\end{array}$ & $\begin{array}{c}\text { Encaixar um } \\
\text { morango no meio } \\
\text { de uma fatia } \\
\text { marrom de torta. }\end{array}$ \\
\hline $\begin{array}{c}\text { Colocar o } \\
\text { hambúrguer } \\
\text { completo em um } \\
\text { prato. }\end{array}$ & $\begin{array}{l}\text { Encaixar a peça } \\
\text { azul da bola. }\end{array}$ & $\begin{array}{l}\text { Colocar o sorvete } \\
\text { lilás completo em } \\
\text { uma tigela. }\end{array}$ & $\begin{array}{l}\text { Encaixar um doce } \\
\text { amarelo no canto } \\
\text { esquerdo da fatia } \\
\text { marrom de torta. }\end{array}$ \\
\hline $\begin{array}{c}\text { Servir o lanche } \\
\text { completo na } \\
\text { bandeja com suco e } \\
\text { batata. }\end{array}$ & $\begin{array}{c}\text { Encaixar a peça } \\
\text { vermelha da bola. }\end{array}$ & $\begin{array}{l}\text { Colocar o sorvete } \\
\text { branco completo em } \\
\text { uma tigela. }\end{array}$ & $\begin{array}{l}\text { Encaixar bombom } \\
\text { amarelo no canto } \\
\text { direito da fatia } \\
\text { marrom de torta. }\end{array}$ \\
\hline
\end{tabular}

Fonte: Autores (2020).

\subsection{Procedimento}

Cada criança foi exposta às fases da pesquisa (descritas a seguir) de forma individual. Foram organizados roteiros fotográficos representando diferentes ações que as crianças deveriam emitir, e os mesmos foram organizados em dois cadernos, sendo um para cada brinquedo.

\section{Primeira fase. Avaliação de pré-requisitos}

Uma vez que a pesquisa buscou estabelecer ações com brinquedos sob controle de fotos, foram realizadas em princípio avaliações de repertórios, que poderiam ser considerados prérequisitos. Foi testado o desempenho das crianças em tarefas de escolha de acordo com o modelo (Matching-to-sample), compreendendo relações de identidade entre objetos; relações de identidade entre figuras; relações visuais-visuais arbitrárias do tipo objeto-figura e figuraobjeto; relações audiovisuais (selecionar objetos e figuras sob controle de seus nomes ditados). Além, disso foi testado o repertório das crianças de seguir instruções verbais, que especificavam ações simples a serem realizadas. Foram selecionados nove pares de objetos e 
de figuras para os testes de relações, mediante o procedimento de escolha de acordo com o modelo. O teste de cada tipo de relação foi realizado a partir da apresentação de nove tentativas discretas. Em cada tentativa, cada criança tinha até 5s para responder. No caso do seguir instruções, 20 instruções para 20 ações motoras simples foram testadas em blocos com 20 tentativas. Em cada tentativa, após uma instrução, cada criança tinha até $5 \mathrm{~s}$ para responder. Durante os testes de todos esses repertórios pré-requisitos mencionados, acertos e erros não produziam consequências diferenciais. Caso uma dada criança não apresentasse um ou mais repertórios, seu ensino seria definido, mas isso não foi necessário para ninguém.

Outra habilidade, considerada pré-requisito para os propósitos da presente pesquisa, referiu-se ao comportamento de virar páginas dos cadernos que continham as fotos das ações a serem realizadas com os brinquedos. Como forma de testar se a criança conseguiria pegar o caderno e virar cada página, apontando para a mesma, uma experimentadora colocou a criança de frente para o caderno, que permaneceu sobre uma mesa. Inicialmente, eram fornecidos minimamente modelos de ajuda física quanto a manipulação do caderno, e como forma de dar alguma pista sobre o que seria esperado por parte da criança. Posteriormente, a criança era posicionada em algumas ocasiões diante do caderno, ao mesmo tempo que era apresentada a instrução verbal "é hora de brincar" (pistas não eram mais apresentadas). Em cada oportunidade, a criança teve até $15 \mathrm{~s}$ para responder. Ao longo de várias tentativas, caso fosse constatado que a criança não apresentaria total autonomia para folhear o caderno, apontando para cada página, essa habilidade seria ensinada. O ensino, sendo necessário, envolveria manipulação de ajuda física quanto a folhear o caderno, com esvanecimento gradual da ajuda e acesso a intervalos de 30 s com reforçadores de preferência da criança.

\section{Segunda fase. Linha de base do comportamento de brincar na presença de fotos}

Para o estabelecimento da linha de base, os componentes de cada brinquedo foram apresentados na mesa separadamente na frente de cada criança, e o livro com as fotos em uma ordem determinada. Uma experimentadora deu instruções para que interagisse com os componentes e os roteiros fotográficos (e.g., dizendo "é hora de brincar"). Cada criança teve até 5s para realizar a ação especificada pela foto de cada página. Como havia nove fotos representando ações diferentes com cada brinquedo, foram administrados blocos de avaliação de linha de base com nove tentativas para cada um dos dois brinquedos. Não foram fornecidas consequências diferenciais para acertos e erros. $\mathrm{O}$ encerramento da condição de linha de base aconteceu mediante a constatação de que cada criança não possuía o repertório de realizar as ações com os brinquedos na presença de fotos, que representavam ações. 


\section{Terceira fase. Teste de instrução genérica}

Esta condição foi semelhante à de linha de base. A diferença foi o fato de que, em cada oportunidade que cada criança teve para responder, na medida que folheava cada página dos cadernos, uma experimentadora apresentava a instrução verbal "faça o que está na foto", como forma de verificar se uma instrução mais geral, que pudesse direcionar a atenção da criança para as fotos, seria suficiente para que um desempenho correto acontecesse. Se esse fosse o caso para uma determinada criança, a mesma seria dispensada da pesquisa.

\section{Quarta fase. Primeira (roteiros fotográficos e pistas de instrução) e segunda condição de intervenção (roteiros fotográficos e pistas por modelação)}

A primeira condição foi conduzida com o primeiro brinquedo de cada criança. Eram administrados blocos com nove tentativas, como na condição de linha de base. Em cada tentativa em que a criança se deparava com uma determinada foto, ela tinha até $5 \mathrm{~s}$ para responder. Quando eram constatados acertos pela emissão de ações de brincar na presença de suas fotos correspondentes, ao longo das tentativas, eram apresentados elogios e a criança acumulava fichas, que poderiam ser posteriormente trocadas por itens de sua preferência (brinquedos, jogos e guloseimas). Quando erros eram cometidos, ou quando não havia resposta, era fornecida primeiramente uma pista, consistindo na descrição da instrução específica, quanto a ação que deveria ser realizada. Caso a criança não respondesse em até $5 \mathrm{~s}$, ou cometesse um erro, uma correção por ajuda física total era conduzida para o encerramento da tentativa.

A segunda condição de intervenção foi conduzida com o segundo brinquedo de cada criança. A administração das tentativas aconteceu de forma semelhante ao caso da primeira condição. A diferença entre as intervenções foi em função do primeiro tipo de pista, ou ajuda, que era apresentada após uma dada tentativa em que um erro era cometido, ou na qual $5 \mathrm{~s}$ teriam passado sem que uma resposta fosse emitida. Em se tratando da segunda condição, uma experimentadora demonstrava a ação, que deveria ser realizada pela criança, para que a mesma imitasse (modelação). Caso isso não fosse suficiente para evocar uma resposta, assim como foi o caso da primeira condição de intervenção, a criança era corrigida de forma mais intrusiva, com ajuda física. As duas condições desta fase eram administradas em alternância ao longo de várias sessões, em função do tipo de delineamento de tratamentos alternados empregado na pesquisa. Não houve a definição de um critério rígido para o encerramento das intervenções, mas foi assumido que o tipo de intervenção, no qual $100 \%$ de acertos em um bloco de tentativas fosse alcançado primeiro, poderia ser considerado o mais eficiente. Ao 
longo dos blocos de tentativas, referentes às duas intervenções, foram realizadas sondas de verificação de controle de estímulos (responder sob controle das fotos ou não), descritas a seguir.

\section{Quinta fase. Sondas de verificação de controle de estímulos}

$\mathrm{Na}$ medida que as duas intervenções em alternância da fase anterior mencionada avançavam, um critério foi definido para a realização de sondas, com o propósito de medir controle de estímulos. Em cada sonda administrada quanto a cada brinquedo, as fotos do caderno eram organizadas sob uma nova ordem/sequência, como forma de medir se o responder, por parte de cada criança, acontecia sob controle das fotos ou de um possível efeito de sequência. A condição para que uma sonda de verificação de controle de estímulos fosse realizada, quanto a cada um dos brinquedos, era de que a intervenção tivesse produzido um desempenho de pelo menos $70 \%$ de acertos em um bloco de tentativas. A administração das tentativas das sondas aconteceu de forma semelhante ao caso da linha de base, ou seja, não foram programadas consequências diferenciais para acertos e erros.

\subsection{Concordância entre observadores}

Uma experimentadora foi responsável pela condução das sessões de avaliação e intervenção, realizando o registro dos dados referentes às respostas das crianças participantes. Os dados também foram coletados e registrados em outra folha de registro, por uma segunda observadora, em aproximadamente $30 \%$ das sessões para as duas crianças, com o objetivo de determinar o grau de concordância entre a experimentadora e a segunda observadora. $\mathrm{O}$ cálculo da concordância foi realizado a partir da divisão do número de concordâncias pelo número de concordâncias somado ao número de discordâncias, e multiplicado por 100 para a determinação de um percentual. Houve $100 \%$ de concordância para as crianças participantes da pesquisa.

\subsection{Delineamento experimental}

O tipo de delineamento utilizado para medir os efeitos das variáveis independentes (VI) (roteiros fotográficos com pistas de instrução verbal ou modelação) sobre a variável dependente (VD) (ações com brinquedos) foi de tratamentos alternados com linha de base inicial (Barlow \& Hayes, 1979; Cooper et al., 2006; Sindelar, Rosenberg \& Wilson, 1985). 
No delineamento de tratamentos alternados, há rápida alternância entre dois ou mais tratamentos diferentes (VI), enquanto os efeitos sobre o comportamento alvo (VD) são medidos. Na presente pesquisa, durante o ensino de repertórios alvo para cada participante, uma das intervenções com um brinquedo compreendeu o uso de roteiros fotográficos, envolvendo instruções verbais como pistas para as ações de brincar. Outro tipo de intervenção com outro brinquedo compreendeu roteiros fotográficos, envolvendo modelação como pista para as ações de brincar. Após a definição de níveis basais das ações na presença dos roteiros, as duas intervenções entraram em vigor com rápida alternância entre elas. Foi assumido que a intervenção que demandasse menor exposição à contingência de ensino, até a aquisição do repertório alvo, seria a mais eficiente.

\subsection{Implicações éticas}

O presente estudo foi aprovado pelo Comitê de Ética em Pesquisa com seres humanos da Universidade CEUMA, São Luís/MA, com o seguinte número de parecer: nº 3.584.016.

\section{Resultados}

Os resultados desta pesquisa estão organizados para cada uma das crianças participantes (P1 e P2), e considerando os brinquedos (1 e 2) em relação aos quais o ensino com roteiros fotográficos foi programado. A Figura 1 e a Figura 2 apresenta, respectivamente, os resultados do ensino de repertório de brincar com o brinquedo 1 (com roteiros fotográficos e pistas de instrução verbal) e com o brinquedo 2 (com roteiros fotográficos e pistas de modelação) para a criança P1. A Figura 3 e a Figura 4 representa os mesmos tipos de procedimentos e de dados com os brinquedos 1 e 2 para a criança P2. A seguir é apresentada a Figura 1 de P1, relacionada a acertos nas respostas de realizar ações com o brinquedo 1 na presença de fotos, e sob condições de linha de base, treino e sondas. 
Figura 1. Acertos nos passos de brincar com o brinquedo 1 por condição, demonstrados por P1. Os dados são apresentados em condições de linha de base, treino e sondas ao longo de 20 blocos tentativas (de B1 a B20).

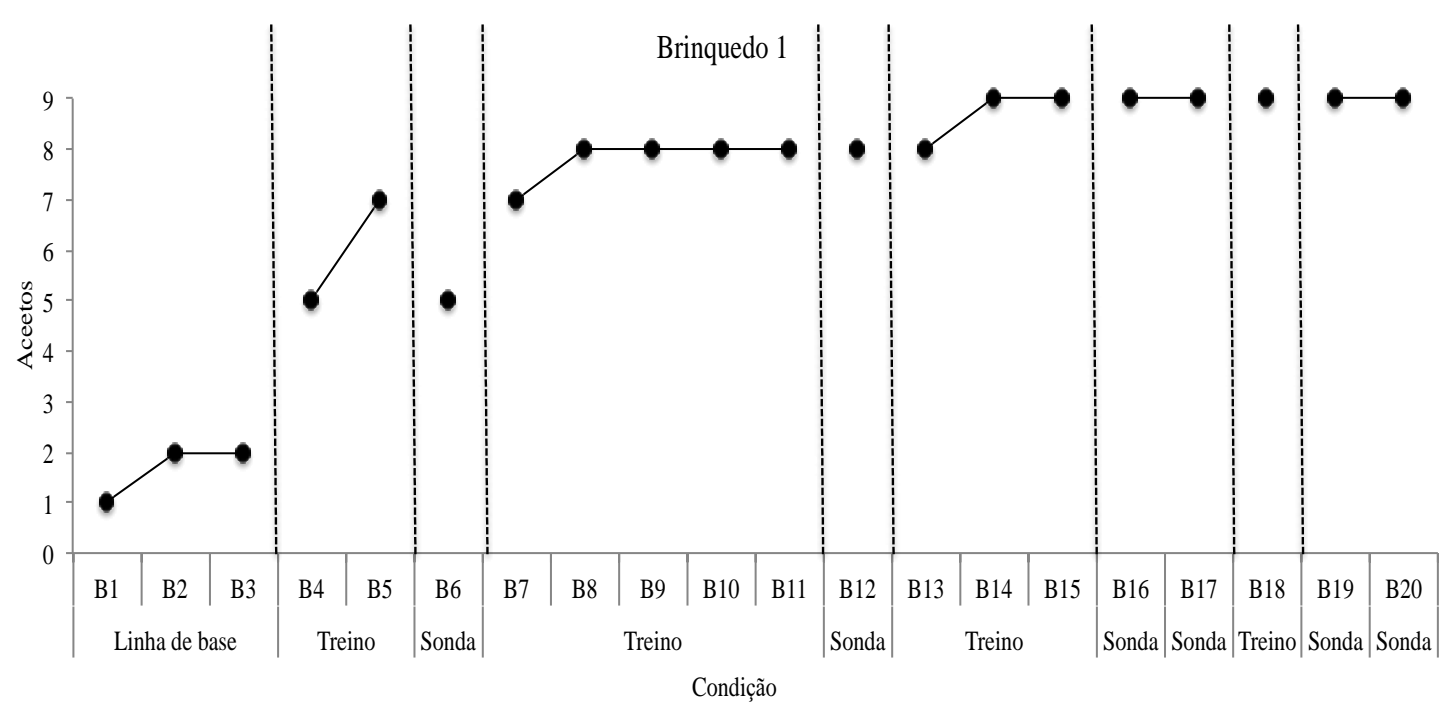

Fonte: Autores (2020).

De acordo com a Figura 1, P1 apresentou até o terceiro bloco de tentativas da condição de linha de base, dois acertos de nove tentativas em que teve oportunidade de responder. Dados referentes ao teste de instrução genérica não foram apresentados, mas esse tipo de instrução foi insuficiente para que a criança demonstrasse respostas corretas de realizar ações com brinquedos na presença das fotos do caderno (esse também foi o caso do brinquedo 2 de $\mathrm{P} 1$, assim como a criança P2 também não demonstrou desempenho correto mediante a instrução genérica com os dois brinquedos). Quando o treino com reforçamento diferencial de respostas corretas, manipulação de pistas de instrução verbal e, se necessário, ajuda física total entrou em vigor, foram necessários nove blocos de tentativas para que P1 demonstrasse acertos em todas as tentativas, o que aconteceu no bloco 14 (B14). Ao longo do treino, seis sondas de verificação de controle de estímulos (do responder na presença de fotos organizadas sob novas sequências) foram conduzidas, em B6, B12, B16, B17, B19 e B20. Nesses blocos de nove tentativas de sonda, P1 apresentou cinco, oito, nove, nove, nove e nove acertos, respectivamente. A Figura 2 apresenta dados referentes a acertos nas respostas de realizar ações com o brinquedo 2 na presença de fotos, e sob condições de linha de base, treino e sondas para $\mathrm{P} 1$. 
Figura 2. Acertos nos passos de brincar com o brinquedo 2 por condição, demonstrados por P1. Os dados são apresentados em condições de linha de base, treino e sondas ao longo de 21 blocos tentativas (de B1 a B21).

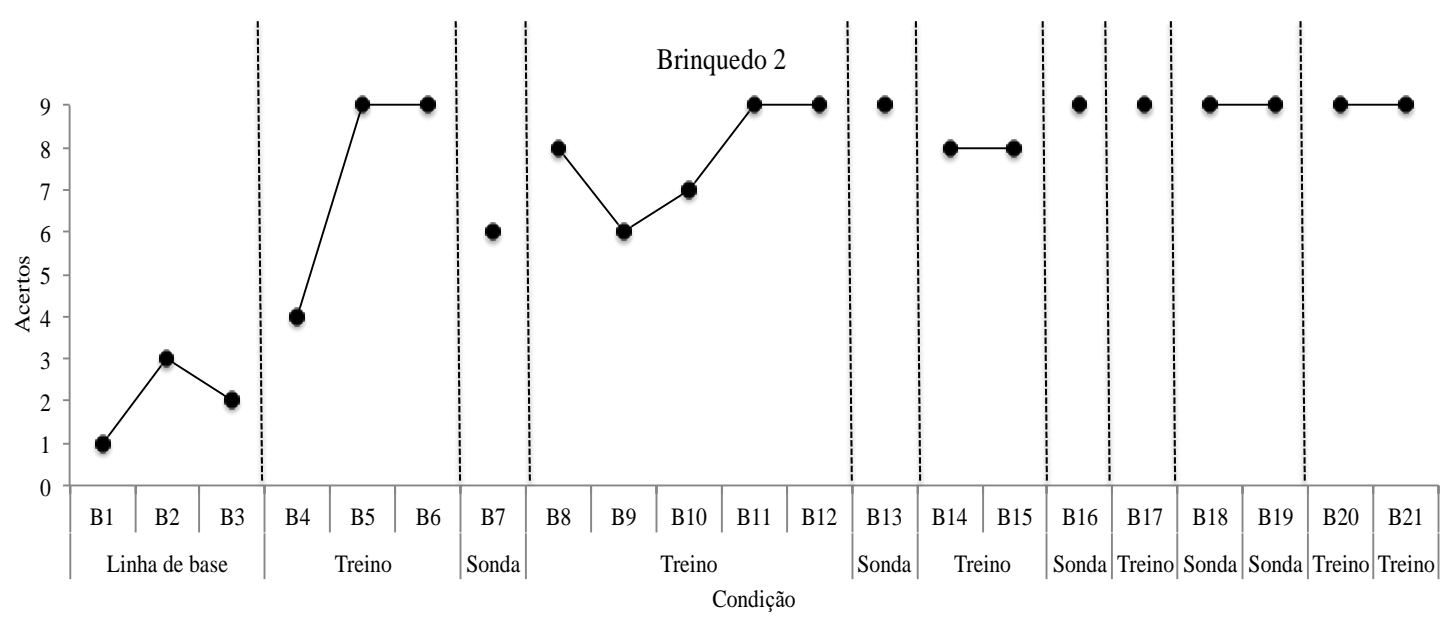

Fonte: Autores (2020).

De acordo com a Figura 2, até o terceiro bloco de uma condição de linha de base, P1 demonstrou dois acertos de nove tentativas. Quando o treino com reforçamento diferencial de respostas corretas, manipulação de pistas de modelação e, se necessário, ajuda física total entrou em vigor, P1 demonstrou nove acertos de nove tentativas em B5, ou seja, o segundo bloco da condição de treino. Ao longo de alguns dos blocos de treino seguintes, o desempenho declinou um pouco, destacando-se oito, seis e sete acertos em B8, B9 e B10, respectivamente e, depois, oito acertos em B14 e B15. Após isso, a criança apresentou nove acertos nos demais blocos de treino da Figura 2. Ao longo do treino foram realizadas cinco sondas de verificação de controle de estímulos. Em relação às mesmas foram identificados seis acertos em B7 e nove acertos em B13, B16, B18 e B19. Na Figura 3 estão os dados correspondentes a acertos nas respostas de realizar ações com o brinquedo 1 na presença de fotos, e sob condições de linha de base, treino e sondas para P2. 
Figura 3. Acertos nos passos de brincar com o brinquedo 1 por condição, demonstrados por P2. Os dados são apresentados em condições de linha de base, treino e sondas ao longo de 13 blocos tentativas (de B1 a B13).

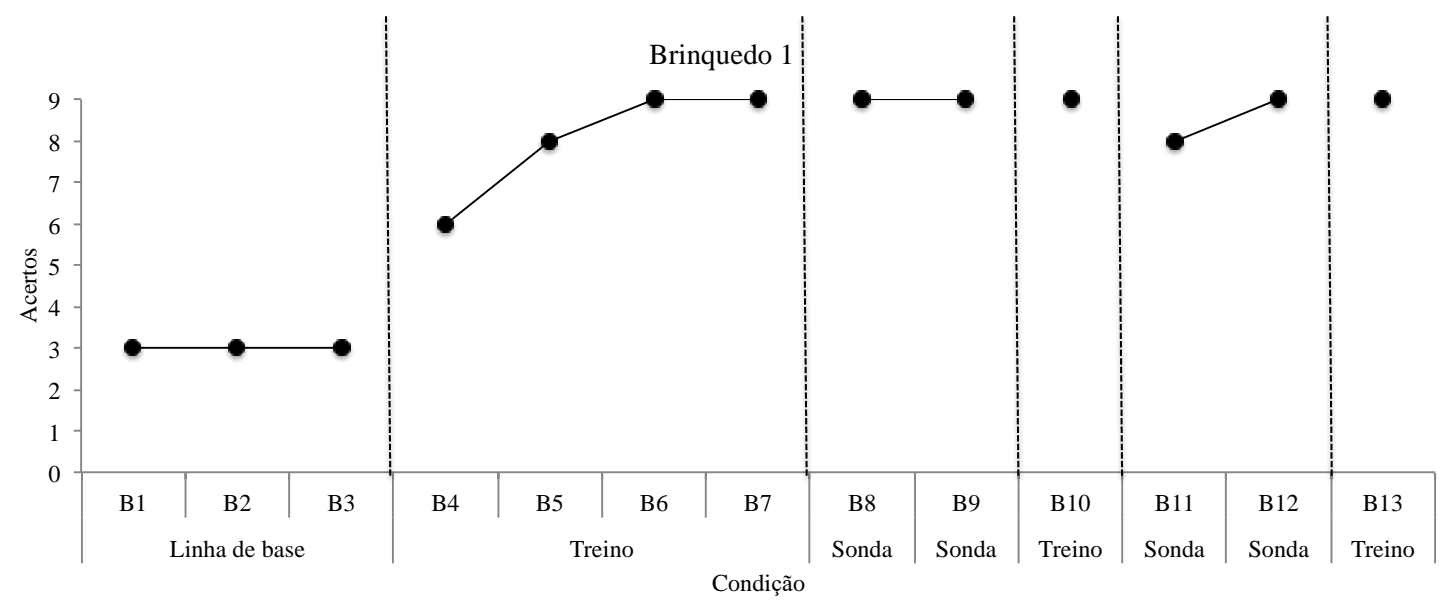

Fonte: Autores (2020).

Conforme pode ser visto na Figura 3, P2 apresentou três acertos até o terceiro bloco da condição de linha de base. Quando o treino com reforçamento diferencial de respostas corretas, manipulação de pistas de instrução verbal e, se necessário, ajuda física total foi iniciado, foram necessários três blocos de tentativas para que nove acertos de nove tentativas fossem demonstrados, e esse desempenho foi mantido nos demais blocos de treino. Ao longo do treino, quatro sondas foram realizadas, sendo que P2 demonstrou nove acertos em B8 e B9, oito acertos em B11 e nove em B12. A Figura 4 revela dados referentes a acertos nas respostas de realizar ações com o brinquedo 2 na presença de fotos, e sob condições de linha de base, treino e sondas para P2. 
Figura 4. Acertos nos passos de brincar com o brinquedo 2 por condição, demonstrados por P2. Os dados são apresentados em condições de linha de base, treino e sondas ao longo de 12 blocos tentativas (de B1 a B12).

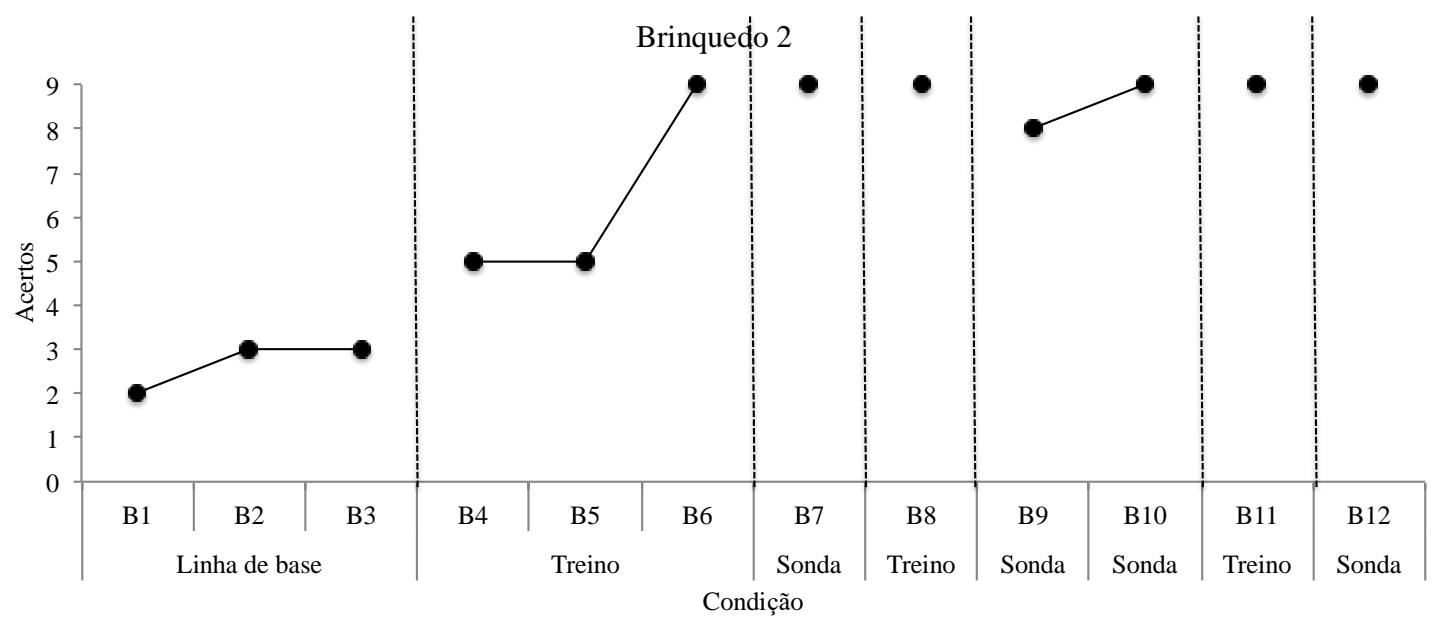

Fonte: Autores (2020).

A Figura 4 revela que, na condição de linha de base, P2 apresentou, até o terceiro bloco de tentativas, três acertos. Quando o treino com reforçamento diferencial de respostas corretas, manipulação de pistas de modelação e, se necessário, ajuda física total foi iniciado, P2 demonstrou nove acertos de nove tentativas em B6, ou seja, no terceiro bloco de treino. Nos demais blocos, esse desempenho foi mantido. Ao longo do treino foram realizadas quatro sondas, destacando-se nove acertos em B7, oito acertos em B9, e nove acertos em B10 e B12.

\section{Discussão}

Na presente pesquisa, um delineamento de tratamentos alternados, com linha de base inicial, foi utilizado com o propósito de comparar os efeitos de dois tipos de pista sobre o estabelecimento de ações com brinquedos na presença de fotos que representavam essas ações. Dois brinquedos foram selecionados para duas crianças com TEA (P1 e P2), que foram as participantes do estudo. Para cada brinquedo foi utilizado um tipo de pista diferente durante a intervenção com roteiros fotográficos, destacando-se instrução verbal para o brinquedo 1 e modelação para o brinquedo 2. Para as duas crianças, ambas as pistas foram eficazes para o ensino dos repertórios de realizar ações com os dois brinquedos na presença de 
fotos, replicando a literatura prévia que já havia demonstrado a eficácia do uso de roteiros fotográficos e pistas no estabelecimento desse tipo de repertório (Akers et al., 2016; Matos et al., 2018; Phillips \& Vollmer, 2012).

Phillips \& Vollmer (2012) e Matos et al. (2018) investigaram os efeitos de diferentes níveis de pistas sobre a emissão de ações de brincar, na presença de fotos que as representavam, em crianças com diagnóstico de TEA. O ensino foi eficaz no sentido de que desempenhos livres do controle de pistas foram estabelecidos nos participantes. A diferença, em relação à presente pesquisa, foi que os estudos prévios compreenderam, na condição de intervenção, uma hierarquia de pistas. Diante de cada foto que representava uma determinada ação com brinquedo, uma dada criança tinha de $5 \mathrm{~s}$ a 10 s para emitir uma resposta. Caso a mesma fosse incorreta, ou não houvesse resposta, o primeiro nível de pista compreendia a apresentação de uma instrução para que a criança realizasse a ação referente ao que a foto mostrava. Caso isso não fosse suficiente, outro nível de pista envolvia um experimentador fornecer uma instrução verbal específica quanto a ação a ser realizada. Se ainda assim não fosse o bastante, instrução verbal específica era fornecida, e um experimentador também apontava para as partes do brinquedo que precisavam ser manipuladas pela criança. Outro nível de pista, caso necessário, envolvia o experimentador demonstrar como a ação com o brinquedo deveria ser realizada, e para que a criança pudesse imitar (modelação). Por fim, caso nenhuma dessas pistas funcionasse, um experimentador guiava a criança fisicamente para que realizasse a ação.

Nos estudos de Phillips \& Vollmer (2012) e Matos et al. (2018) não foi possível isolar os efeitos de cada tipo de pista empregado sobre o estabelecimento de repertórios de brincar na presença de fotos. No presente trabalho, dois tipos de pistas (instrução verbal e modelação), também utilizados nos dois estudos anteriores mencionados, foram comparados quanto aos seus efeitos sobre a realização de ações com brinquedos na presença de fotos, por meio de um delineamento com tratamentos alternados. Cada intervenção compreendeu um tipo de pista com um brinquedo diferente, e para uma mesma criança. Ambas as pistas foram eficazes para a aprendizagem do repertório alvo. No caso da criança P1, os dados de evolução com o brinquedo 2, que envolveu manipulação de pistas de modelação, sugerem que essa ajuda foi mais eficiente do que o caso da instrução verbal com o brinquedo 1 . Nove blocos de tentativas foram necessários para o estabelecimento de um responder livre de erros com o brinquedo 1, e apenas dois blocos com o brinquedo 2. Neste caso, o desempenho piorou um pouco nos blocos B8, B9 e B10 (com oito, seis e sete acertos, respectivamente) e nos blocos B14 e B15 (com oito acertos), mas um responder livre de erros foi restabelecido nos blocos 
seguintes de treino. No caso da criança P2, os dois casos de ajuda, instrução verbal e modelação, foram eficientes em uma medida semelhante com os brinquedos, pois em ambos os casos foram necessários três blocos de tentativas para a emissão de respostas sem erros.

Neste estudo, brinquedos selecionados, fotos e ações definidas foram organizados de forma que o nível de complexidade das tarefas fosse semelhante (mas não se pode descartar a possibilidade de ter havido diferenças). As crianças evoluíram rapidamente com ambos os brinquedos, independente das diferenças de desempenho com os dois tipos de pistas, sendo que as diferenças de desempenho entre as intervenções foram mais acentuadas no caso da criança 1. Considera-se o tipo de delineamento utilizado relevante, uma vez que pode indicar procedimento(s) de ensino que demanda menor exposição à contingência para a instalação do repertório alvo, sendo, portanto, mais eficiente. Isso é algo valorizado na ABA do ponto de vista científico e, também social, uma vez que é importante investigar procedimentos que possam produzir aquisição de repertórios no menor tempo possível para crianças com TEA, o que pode ajudar a reduzir o atraso em relação ao desenvolvimento considerado típico.

Algo que não foi empregado na presente pesquisa, e que seria importante por propósito de controle experimental das intervenções sobre as ações independentes com brinquedos, foi a introdução de um terceiro brinquedo que permanecesse sempre em condição de linha de base, servindo como grupo controle (Cooper et al., 2006). Futuras pesquisas sobre o tema, e que se proponham a comparar tipos de intervenção para a aquisição de repertório de brincar na presença de fotos de ações com brinquedos, poderiam manipular um brinquedo, e seus roteiros fotográficos, como grupo controle. Uma vez que o desempenho com o brinquedo manipulado como controle permanecesse baixo e inalterado, em relação a casos relacionados a intervenções com outros brinquedos, isso poderia representar uma medida de que as aquisições de repertório de brincar seriam função das intervenções.

Por outro lado, é importante destacar que, em pesquisas prévias sobre o tema (Matos et al., 2018; Phillips \& Vollmer, 2012), houve participantes que demonstraram aquisição de repertório de ações de brincar com brinquedos que foram manipulados apenas em condição de linha de base. Os autores consideraram que esse dado representou uma medida de generalização, uma vez que houve previamente a aquisição de repertórios com outros brinquedos sob intervenção, a partir do uso de diferentes tipos de pista e reforçamento de desempenhos independentes. Tal fenômeno de generalização, possivelmente, foi favorecido pelo tipo de delineamento experimental utilizado nos estudos mencionados (linha de base múltipla ou ainda uma variação desse caso, sondas múltiplas). Em se tratando de futuras pesquisas que possam utilizar um delineamento de tratamentos alternados com linha de base 
inicial, e tendo um brinquedo específico representando um grupo controle, uma possível aquisição de ações com esse brinquedo em situação de linha de base poderia ser interpretada como generalização do treino com outros brinquedos também, ainda que isso pudesse comprometer em alguma medida o estabelecimento de controle experimental.

Em se tratando deste estudo, além da questão do controle experimental, que poderia ter sido melhorada com a introdução de um terceiro brinquedo na condição de grupo controle, vale destacar que não foram manipuladas condições de generalização e de manutenção de repertório. Todas as condições da pesquisa foram implementadas em ambiente estruturado de sala de um laboratório de avaliação, pesquisa e intervenção de uma Universidade privada. $\mathrm{Na}$ pesquisa de Phillips \& Vollmer (2012), avaliações e intervenções foram realizadas em contexto escolar. Teria sido interessante e importante, no presente estudo, a realização de sondas em contexto de escola regular das crianças com TEA, como forma de medir generalização em ambiente novo, assim como o processo poderia ser mediado por outra pessoa como, por exemplo, um professor. Em uma pesquisa aplicada a aprendizes com desenvolvimento atípico, sabe-se que os repertórios trabalhados precisam ser socialmente relevantes e a generalização deve ser uma das principais metas (Baer, Wolf \& Risley, 1968).

Medidas de generalização em contextos que representam mais fielmente o dia a dia de uma criança, e com pessoas que fazem parte desses contextos, tem alta relevância social. Além disso, a escola é um espaço em que atividades lúdicas, relacionadas a brincar, também são conduzidas e são importantes no sentido de impulsionar o desenvolvimento das crianças, inclusive no nível das relações com seus pares de mesma idade. Futuras pesquisas poderiam realizar o ensino de repertórios de brincar na presença de roteiros fotográficos em contexto análogo (como o de um laboratório), e medir a generalização em contexto de escola regular, tendo pessoas desse espaço, inclusive, como mediadoras (e.g., professores e outras crianças).

Vale destacar também que, em princípio, avaliação de generalização em ambiente novo era uma das metas do presente estudo. Com a pandemia do novo coronavírus (COVID19) em março de 2020, a necessidade de isolamento social, a partir de orientações de instâncias governamentais e de saúde, não permitiu que a generalização fosse investigada. É importante destacar, ainda, que todos os dados do estudo, que foram apresentados neste manuscrito, foram coletados com as crianças com TEA participantes antes do início da pandemia. A manutenção dos repertórios adquiridos também era uma meta desta pesquisa, mas não foi possível também por causa da pandemia. Novas pesquisas poderiam também medir a manutenção de repertórios, por exemplo, um mês após a conclusão de intervenções. Sabe-se que as intervenções mais relevantes do ponto de vista social e científico, em se 
tratando de pesquisa aplicada, são aquelas que asseguram efeitos duradouros de aquisição de repertórios ensinados.

\section{Considerações Finais}

A presente pesquisa replicou e estendeu o que a literatura prévia produziu sobre ensino de repertório de brincar funcional sob controle de roteiros fotográficos, que representavam sequências de ações a serem realizadas. Sabe-se que, uma vez que déficits em relação a esse tipo de habilidade sejam rastreados e confirmados em crianças com diagnóstico de TEA, procedimentos especializados e que assegurem seu ensino se tornam importantes. $\mathrm{O}$ brincar de forma funcional é algo que faz parte do desenvolvimento das crianças com desenvolvimento típico de um modo geral. Ensinar esse tipo de repertório para crianças com TEA é importante, uma vez que existe uma grande demanda social quanto a aprendizes com esse perfil demonstrarem aquisição de habilidades que possam aproximar seu desenvolvimento dos padrões que são considerados típicos. Além disso, trata-se esse de um tipo de repertório que tem relevância para o estabelecimento de relações sociais, especialmente considerando o caso dos pares de mesma idade e com desenvolvimento típico. As relações entre as crianças, de um modo geral, representam experiências nas quais o lúdico, as brincadeiras são exploradas. Considera-se em função disso, sobretudo, que investigações como as da presente pesquisa têm, além de implicações científicas quanto a variáveis que são responsáveis pela aquisição de repertório de brincar, grande relevância social, uma vez que ajuda a melhorar o desenvolvimento da criança também no nível das relações sociais, favorecendo processos de inclusão.

Novos estudos poderiam ser conduzidos com o propósito de replicar os procedimentos do presente trabalho com outras crianças com TEA. Isso deverá servir a função de testar a generalidade dos procedimentos quanto a aquisição de repertórios de brincar na presença de roteiros fotográficos, envolvendo outras crianças. Além disso, comparar os efeitos de diferentes tipos de pistas sobre a aquisição de repertórios de brincar em novos participantes seria também importante, assim como foi na presente pesquisa, para isolar o tipo de pista mais eficiente no ensino. Neste estudo, a generalização de ações de brincar não foi medida em um novo ambiente, e nem com novos brinquedos, assim como não foi avaliada a manutenção das habilidades adquiridas após o encerramento das intervenções em função da pandemia do novo coronavírus (COVID-19). Novos trabalhos poderiam, nesse sentido, medir a generalização e manutenção de ganhos de habilidades semanas após o encerramento das intervenções. Tais 
medidas podem ajudar a conferir maior relevância científica e social para pesquisas com ênfase em Análise do Comportamento Aplicada ao TEA.

\section{Referências}

Akers, JS, Higbee, TS, Pollard, JS, Pellegrino, AJ \& Gerencser, KR. (2016). An evaluation of photographic activity schedules to increase independent playground skills in young children with autism. Journal of Applied Behavior Analysis, 49, 954-959.

Allen, KD \& Cowan, RJ. (2008). Naturalistic teaching procedures. In: Luisell, JK, Russo, DC, Christian, WP \& Wilczynski, SM. (Eds.). Effective practices for children with autism (pp. 240-270). New York: OXFORD.

American Psychiatry Association (2013). Diagnostic and statistical manual of mental disorders - DSM-5 (5th.ed). Washington: American Psychiatric Association.

Baer, DM, Wolf, MM \& Risley, TR. (1968). Some current dimensions of applied behavior analysis. Journal of Applied Behavior Analysis, 1, 91-97.

Barlow, DH \& Hayes, SC. (1979). Alternating treatments design: one strategy for comparing the effects of two treatments in a single subject. Journal of Applied Behavior Analysis, 12, 199-210.

Brito, N. (2011). O brincar e a análise do comportamento. Disponível em: https://www.comportese.com/2011/11/o-brincar-e-a-analise-do-comportamento. Acesso em: 10 ago. 2019.

Brunoni, D, Mercadante, M \& Schwartzman, JS. (2014). Transtornos do espectro do autismo. In: Lopes, AC (Ed). Clínica Médica: Diagnóstico e tratamento (pp. 148-154). São Paulo: Atheneu.

Cooper, JO, Heron, TE \& Heward, WL. (2006). Applied behavior analysis. Second edition. New Jersey: Pearson Merry Prentice Hall. 
Goulart, P \& Assis, GJA (2002). Estudos sobre autismo em análise do comportamento: aspectos metodológicos. Revista Brasileira de Terapia Comportamental e Cognitiva, 4, 151165.

Johnson, BF \& Cuvo, AJ. (1981). Teaching mentally retarded adults to cook. Behavior Modification, 3, 187-202.

Lear, K. (2004). Help us learn: A self-paced training program for ABA. Ontario: Canada.

Lovaas, OI. (1987). Behavioral treatment and normal education and intellectual functioning in young autistic children. Journal of Consulting and Clinical Psychology, 55, 3-9.

MacDuff, GS, Krantz, PJ \& McClannahan, LE. (1993). Teaching children with autism to use photographic activity schedules: Maintenance and generalization of complex response chains. Journal of Applied Behavior Analysis, 26, 89-97.

Martin, JE, Rusch, FR, James, VL, Decker, PJ \& Trtol, KA. (1982). The use of picture cues to establish self-control in the preparation of complex meals by mentally retarded adults. Applied Research in Mental Retardation, 3, 105-119.

Matos, DC. (2016). Análise do comportamento aplicada ao desenvolvimento atípico com ênfase em autism. Porto Velho: AICSA.

Matos, DC \& Matos, PGS. (2018) Intervenções em psicologia para inclusão escolar de crianças autistas: estudo de caso. Revista Espaço Acadêmico, 211, 21-31.

Matos, DC, Matos, PGS, Araújo, CX, Ribeiro, CG \& Melo, ERMSF. (2018). The establishment of functional play behaviors in children with autism: implications for school inclusion. Creative Education, 9, 1910-1930.

Matos, DC, Silva, FMAM, Firmo, WCA \& Matos, PGS. (2020). Training psychology interns to teach verbal and non-verbal repertoires in children with autism spectrum disorder. Research Society and Development, 9, 1-24. 
Minarovic, TJ \& Bambara, LM. (2007). Teaching employees with intellectual disabilities to manage changing work routines using varied sight-word checklists. Research \& Practice for Persons with Severe Disabilities. 32, 31-42.

Pereira, AS, Shitsuka, DM, Parreira, FJ \& Shitsuka, R. (2018). Metodologia do trabalho científico. Santa Maria: UAB / NTE / UFSM.

Phillips, CL \& Vollmer, TR. (2012). Generalized Instruction Following with Pictorial Prompts. Journal of Applied Behavior Analysis, 45, 37-54.

Pierce, KL \& Schreibman, L. (1994). Teaching daily living skills to children with autism in unsupervised settings through pictorial self-management. Journal of Applied Behavior Analysis, 27, 471-481.

Sindelar, PT, Rosenberg, MS \& Wilson, RJ. (1985). An adapted alternating treatments design for instructional research. Education and Treatment of Children, 8, 67-76.

Smith, T. (2001). Discrete trial training in the treatment of autism. Focus on Autism and Other Developmental Disabilities, 16, 86-92.

Sowers, J, Verdi, M, Bourbeau, P \& Sheehan, M. (1985) Teaching job independence and flexibility to mentally retarded students through the use of a self-control package. Journal of Applied Behavior Analysis, 18, 81-85, 1985.

Varella, A \& Souza, C. (2018). Ensino por tentativas discretas: Revisão sistemática dos estudos sobre treinamento com vídeo modelação. Revista Brasileira de Terapia Comportamental e Cognitiva, 20, 73-85.

Wacker, DP \& Berg, WK. (1983). Effects of picture prompts on the acquisition of complex vocational tasks by mentally retarded adolescents. Journal of Applied Behavior Analysis,16, 417-433. 
Wacker, DP, Berg, WK, Berrie, P \& Swatta, P. (1985). Generalization and maintenance of complex skills by severely handicapped adolescents following picture prompt training. Journal of Applied Behavior Analysis, 18, 329-336.

Williams, E, Redd, V \& Costall, A. (2001). Taking a closer look at functional play in children with autism. Journal of Autism and Developmental Disorders, 31, 67-77.

\section{Porcentagem de contribuição de cada autor no manuscrito}

Amanda Lima Rubim - $50 \%$

Daniel Carvalho de Matos - $50 \%$ 